\title{
5 \\ Numerical Techniques for Overland Flow from Pavement
}

William James and Stuart C. Wylie

In this chapter we discuss the fundamental processes of flow over pavement, and how they may be solved numerically. The discussion reveals additionally, a flow in the recession curve over and above that normally considered. This additional flow is similar to the anomalous pip and called the anomalous hump.

Hyperbolic equations, in which category the dynamic wave equations fall, are those for which $\left(b^{2}-4 a c\right)$ is greater than zero in the general equation for any dependent variable U:

$$
a \cdot \frac{\partial^{2} U}{\partial x^{2}}+b \cdot \frac{\partial^{2} U}{\partial x \partial t}+c \cdot \frac{\partial^{2} U}{\partial t^{2}}+d \cdot \frac{\partial U}{\partial x}+e \cdot \frac{\partial U}{\partial t}+f \cdot U+g=0
$$

Such phenomena are characterized by disturbances that propagate seemingly uncontrollably away from a stationary observer. In the case where $\left(b^{2}-4 a c\right)$ equals zero, the equation is said to be parabolic, and when $\left(b^{2}-4 a c\right)$ is less than zero, elliptic. Parabolic equations describe processes that are slow and damped, like groundwater flow. Elliptical equations describe steady-state problems. These coefficients appear also in equation (5.2) whose roots are the slopes of the characteristic curves when the partial differential equation is reduced to one involving total differentials only:

James, W. and S.C. Wylie. 2000. "Numerical Techniques for Overland Flow from Pavement." Journal of Water Management Modeling R206-05. doi: 10.14796/JWMM.R206-05.

(C) CHI 2000 www.chijournal.org ISSN: 2292-6062 (Formerly in Applied Modeling of Urban

Water Systems. ISBN: 0-9683681-3-1) 


$$
a\left(\frac{d t}{d x}\right)^{2}-b\left(\frac{d t}{d x}\right)+c=0
$$

If the coefficients $\mathrm{a}, \mathrm{b}, \ldots \mathrm{g}$ are constants or functions of $\mathrm{x}$ and $\mathrm{t}$ only, the partial differential equation is said to be linear. If the coefficients of the secondorder derivatives are functions of $\mathrm{x}, \mathrm{t}, \mathrm{U}, \partial \mathrm{U} / \partial \mathrm{x}$ and $\partial \mathrm{U} / \partial \mathrm{t}$, but not of secondorder derivatives, the equation is described as quasi-linear, even though it is nonlinear. The dynamic wave equations, with which this chapter is concerned, are of this type. (A linear equation is one for which the sum of separate solutions is also a solution).

\subsubsection{The Dynamic Wave Equations}

The well-known equations of unsteady, spatially-varied flow on an impervious surface are:

Momentum: $\quad \frac{\partial v}{\partial t}+v \cdot \frac{\partial v}{\partial x}+g\left(\frac{\partial h}{\partial x}+S_{f}-S_{b}\right)+\frac{q v}{h}=0$

Continuity:

$$
h \cdot \frac{\partial v}{\partial x}+v \cdot \frac{\partial h}{\partial x}+\frac{\partial h}{\partial t}=q
$$

In these equations,

$$
\begin{aligned}
\mathrm{x} & =\text { distance along the channel, } \\
\mathrm{t} & =\text { time, } \\
\mathrm{h} & =\text { depth of flow, } \\
\mathrm{v} & =\text { average velocity of flow, } \\
\mathrm{S}_{\mathrm{b}} & =\text { channel bottom slope } \\
\mathrm{S}_{\mathrm{f}} & =\text { friction slope } \\
\mathrm{g} & =\text { acceleration due to gravity } \\
\mathrm{q} & =\text { precipitation intensity. }
\end{aligned}
$$

The one-dimensional form of the equations is used here, because this form is highly suited to the presentation of the basic concepts of the numerical procedures to be discussed. Extension to irregular surfaces can be accomplished with little difficulty. Derivation of these equations is given in standard reference works (e.g. Chow, 1959, 1969; Henderson, 1966; Daily and Harleman, 1966; Grace and Eagleson, 1965, 1966), and follows from the following assumptions:

- a moderately wide flow surface ( $h / w i d t h ~ \ll 1)$,

- small bottom slope $(\theta \cong \sin \theta \cong \tan \theta)$, 
- uniform velocity distribution (momentum distribution coefficient is unity),

- overpressure due to vertical inflow is negligible,

- precipitation has negligible effect on flow dynamics (Eagleson, 1970) in comparison with that of gravity,

- friction slope for steady, uniform flow applies to unsteady, nonuniform flow of the same depth and average velocity.

Formulation of the dynamic wave equations is reviewed here since this has more general application than the simpler kinematic formulation.

Woolhiser and Liggett (1967) found the kinematic wave formulation to be sufficiently accurate for most practical overland flow problems. To determine when satisfactory overland flow solutions can be obtained from the kinematic wave method, they introduced the dimensionless numbers:

$$
\text { kinematic flow number }=\frac{\mathrm{S}_{\mathrm{b}} \mathrm{L}_{\mathrm{o}}}{\mathrm{H}_{\mathrm{o}} \mathrm{F}_{\mathrm{o}}^{2}}
$$

Here

$\mathrm{S}_{\mathrm{b}}$ is bed slope,

$L_{0}$ is the bed length,

$\mathrm{H}_{\mathrm{o}}$ is the normal depth at the downstream overfall and

$F_{0}$ is the Froude number for normal flow at $x=L_{0}$, and

$$
F_{0}=\frac{V_{0}}{\sqrt{\left(g \cdot H_{0}\right)}}
$$

where:

$$
\mathrm{V}_{\mathrm{o}}=\text { the normal velocity at the downstream end of the bed. }
$$

If the kinematic flow number is less than 10 , the dynamic wave formulation should be used (values smaller than 10 occur more often for short, smooth beds with small slopes and high input). When the kinematic flow number exceeds 20 , the kinematic wave approximation is considered to be good (Liggett and Woolhiser, 1967).

\subsubsection{Historical Review}

The dynamic wave equations have been known for some time and various forms are sometimes referred to as the shallow water wave or $d e S t$. Venant equations, after the 19th century French mathematician. However, the first serious attempts to apply these equations to overland flow problems have been comparatively recent, after the introduction of computers. Primarily because there is no general analytic solution to this system of equations for the complex flow conditions almost always obtaining, numerical procedures are used. Analytic solutions have 
been restricted to limited regions of the solution domain or to special cases where suitable simplifications could be made. Graphical and numerical solutions have been obtained for some special cases, but, unfortunately, graphical techniques are tedious, and many of the finite-difference schemes have exhibited difficulty in converging.

Intense work on this subject was carried out in the late 60 s. Woolhiser and Liggett (1967) reviewed the literature. Morgali and Linsley (1965) used finite difference solutions to the shallow water equations in simulating runoff from real catchments. Brakensiek (1966) and Brakensiek et al. (1966) also used numerical methods in computing runoff from rural catchments, and Schaake (1965) used the same approach for urban catchments.

Several workers have employed the kinematic formulation of the wave equations. Eagleson (1970) reports that Iwagaki (1955) was the first investigator to use the kinematic wave method, incorporating a continuous lateral inflow, to analyze in detail the hydrographs of overland flow and of streamflow. Lighthill and Whitham (1955) presented a general treatment of the theory, in which they developed the kinematic wave equations for overland flow and suggested that, when the lateral inflow is a function of time and distance, the solution may be found by numerical integration along the characteristics. They also showed that an explicit solution could be obtained when the lateral inflow is constant or a function of distance only. Henderson and Wooding (1964), Wooding (1965) and Schreiber (1970) used kinematic wave theory for the solution of hydrologic problems.

Chen and Hansen (1966) examined the characteristics of flow profiles and discharge-depth relationships with distance and time as independent variables, and introduced a dimensionless formulation of the continuity and momentum equations. Yu and McNown (1964) used the dynamic formulation of the wave equations in their study of flow on impervious surfaces, and compared their numerical results with experimental data obtained by the Los Angeles District of the Corps of Engineers. Overland flow was studied experimentally by Izzard and Augustine (1943), Izzard (1946), Woo and Brater (1962), Ragan (1966), Robertson et al. (1966), and McCool et al. (1966). James and Horne (1969), used a finite difference scheme for the solution of the equations in their study of tidal propagation in the St. Lucia estuary in South Africa.

Success in the numerical integration of the dynamic wave equations has often been limited, owing in part to the complexity of the boundary conditions, the often poorly posed nature of the problems, and to some unfortunate choices of finite-difference schemes (Liggett and Woolhiser, 1967b). Difficulties that arise from the choice of an unsatisfactory scheme are considered later. In this chapter we disclose some of the problems encountered in the application of a particular explicit direct finite-difference scheme and compare the results obtained from this scheme with those from an implicit direct finite-difference 
scheme. Computed hydrographs are then compared to those measured using the impervious pavement laboratory rig described in the next chapter.

Many recent publications are also available, for example Lapidus and Pinder (1982) and Wylie et al. (1993). They do not change the essentials of this review.

\subsection{Difference Solutions of the Dynamic Wave Equations}

Partial differential equations may be solved numerically by replacing derivatives at a point with difference quotients over a small interval, i.e. $\partial \phi / \partial x$ is replaced by $\Delta \phi / \Delta x$, where $\Delta x$ is small. This manipulation amounts to replacing the differential equations with corresponding algebraic equations. No major simplifications need be made to the unsteady flow equations, but, as Brakensiek (1967) illustrates, the procedure for representing the partial differential equations by algebraic equations is fraught with difficulties. Many factors, such as accuracy, convergence, efficiency and stability, must be considered.

Finite-difference methods are approximate only in the sense that derivatives at a point are approximated by difference quotients over a small interval. Observed data are invariably subject to errors of measurement; and all arithmetical work is limited to a finite number of significant figures and contains roundingoff errors, so even analytical solutions provide only approximate numerical answers. Finite-difference methods can generally give solutions that are either as accurate as the data warrant, or as accurate as is necessary for the technical purposes for which the solutions are required. In both cases, a finite difference solution is often as satisfactory as one calculated from an analytical formula.

Numerical integration techniques used to solve the wave equations are classified as either direct methods or characteristic methods. In the latter case, the equations are transformed into their characteristic form before utilizing the finite-difference representation. No transformation is required before using finite differences in the direct methods. A fixed rectangular network in the $\mathrm{x}$-t plane is used to identify points at which solutions are obtained by direct methods. On the other hand, solution points are identified in the characteristic methods by the intersection of characteristic curves in the x-t plane, or at rectangular network points by interpolation between characteristic curve intersections.

Finite-difference schemes may be classified further as either explicit or implicit. In an explicit scheme, the solution at a given time step depend only on the known solution from the previous time step. In an implicit scheme the solution at a given time step depend on both the known solution at the previous time step and on the adjacent unknown solution at the given time step. The unknowns in the finite-difference equations of an explicit scheme can be evaluated directly, whereas the equations of an implicit scheme generally are solved by iteration. 
Comparisons of the various finite difference schemes have been reported in the literature. Brakensiek (1967) discussed finite difference calculus and its role in solving certain problems. He considered both direct explicit and direct implicit methods and compared error growth for the various schemes applied to the kinematic formulation of the unsteady flow equations. Implicit schemes were found to be far more stable than were explicit schemes. Liggett and Woolhiser (1967b) examined several finite difference schemes for the dynamic formulation of the wave equations, with regard to convergence to the true solutions. They concluded that both characteristic and direct implicit schemes provide stable solutions, while direct explicit schemes were generally unsatisfactory.

\subsection{Convergence and Stability}

Conditions that must be satisfied for the solution of the finite-difference equations to be a reasonably accurate approximation to the solution of the corresponding partial differential equations are associated with:

- firstly, the convergence of the solution of the approximating equations to the solution of the differential equations, and

- secondly, with the stable decay of errors in the arithmetical operations employed in the solutions of the finite-difference equations.

If $U$ represents the exact solution of a partial differential equation with independent variables $\mathrm{x}$ and $\mathrm{t}$, and $\mathrm{u}$ the exact solution of the difference equation used to approximate the partial differential equation, then the finite-difference solution is convergent if $\mathrm{u}$ tends to $\mathrm{U}$ as $\Delta \mathrm{x}$ and $\Delta \mathrm{t}$ both tend to zero. Conditions under which $u$ converges to $U$ have been established for linear partial differential equations with solutions satisfying fairly general boundary and initial conditions, but they are not yet known for non-linear equations, except in a few particular instances. The difference ( $U-u)$ is the discretization error (Smith, 1965), the magnitude of which, at any mesh point, depends on the mesh size, i.e. on $\Delta x$ and $\Delta t$, and on the number of finite-differences in the truncated series used to approximate the derivatives. The more terms used in the series, the better will be the approximation, but a greater number of pivotal values are then involved in the solution.

In general, the discretization error can be reduced by decreasing $\Delta x$ and $\Delta t$, subject usually to some conditional relationship between them. As this leads to an increase in the number of equations to be solved, a solution is limited by such factors as computer time and memory and the accuracy required. The problem of convergence is difficult to investigate usefully, because the final expression for the discretization error is generally in terms of unknown derivatives for which no upper and lower bounds can be estimated. 
If all calculations in a solution could be taken to an infinite number of decimal places, an exact solution of the finite-difference equations would be obtained. However, calculations are taken to only a finite number of decimal places. This procedure introduces a round-off error with each calculation, and the solution computed is not $\mathrm{u}$, but a numerical solution, $\mathrm{N}$.

Generally, a set of finite-difference equations is stable when the cumulative effect of all rounding errors is negligible. More specifically, if the moduli of errors introduced at mesh points are each less than the first difference $(\delta)$, then the finite-difference equations are stable when the maximum value of $(\mathrm{u}-\mathrm{N})$ tends to zero as $\delta$ tends to zero and does not increase exponentially with the number of rows of calculation (i.e. with $j$ for all $i$ where $j$ is in time and $i$ is in distance dimensions). Errors which persist as linear combinations of the initial errors may be tolerable, provided their sum remains much smaller than u (Smith, 1965). Numerical solutions are invariably more accurate than estimates of $(u-N)$ indicate, because stability analysis always assumes that all errors have the same sign, which is not the case. Stability is discussed in detail by Richtmyer (1957).

It is difficult to separate the concepts of stability and convergence. A difference scheme which is a poor approximation of a particular differential equation will approach a different equation as the mesh size approaches zero. Such a scheme may be stable, but the solution of the difference equation does not converge to the solution of the particular differential equation. Conversely, a scheme that is a good approximation of the differential equation may be unstable. Numerical studies seem to indicate that the discretization error is dominant in a stable and convergent process.

\subsection{Finite-difference Methods}

\subsubsection{The Method of Characteristics}

The method of characteristics is described in detail by Abbott (1966). In general, the method of characteristics provides the most accurate procedure for solving hyperbolic equations, since the roots of equation (5.2), which are the slopes of the characteristic curves and have been referred to already, are real and distinct, i.e. $\left(b^{2}-4 a c\right)>0$. It is probably the most convenient method as well, when the initial data are discontinuous, because the propagation of the discontinuities into the solution domain along the characteristics is difficult to deal with on any grid, other than a grid of characteristics (Smith, 1965). Problems involving no discontinuities can be solved satisfactorily by convergent and stable finitedifference methods using rectangular grids, for which computer programs are simpler than those required for solution by the method of characteristics. 
Solutions of the dynamic wave equations are given by the intersections of the two sets of advancing and receding characteristic curves. The slope of an advancing and receding characteristic is given by

$$
\begin{aligned}
& \frac{d x}{d t}=v+c \\
& \frac{d x}{d t}=v-c
\end{aligned}
$$

in which:

$$
\begin{aligned}
& v=\text { flow velocity } \\
& \mathrm{c}=(\mathrm{gh})^{1 / 2}=\text { wave celerity, and } \\
& \mathrm{h}=\text { flow depth. }
\end{aligned}
$$

Furthermore,

$$
d v \pm 2 d c-g\left(S_{b}-S_{f}\right) d t=0
$$

along the advancing and receding characteristics, respectively, if the momentum exchange term qv/h is ignored (Amein, 1966; Liggett, 1959). These equations are integrated numerically to obtain a solution.

The chief advantages of the method are accuracy and speed. Accuracy is largely a consequence of following the characteristics (along which disturbances travel) with the solution. The characteristics also tend to be closer together in areas of rapid change, thus creating a favorable mesh-point spacing.

One of the most difficult initial conditions is that represented by a dry surface with lateral inflow (e.g. rain on pavement) beginning at $t=0$ : namely, $\mathrm{v}=0$ and $\mathrm{h}=0$ at $\mathrm{t}=0$ for $0 \leq \mathrm{x} \leq \ell$. This initial condition represents a type of singularity and may lead to difficulty if used directly in a difference scheme. The characteristic method allows the finite-difference scheme to begin at a time after $t=0$, when non-zero data are already known, and so avoids this difficulty.

The chief disadvantage of the characteristic method is that the data at intermediate points in the $\mathrm{x}$-t plane are not easily obtained in an acceptable form. The method often involves tedious interpolations and necessitates large computer storage.

Vreugdenhil (1968) rejects the method of characteristics for three reasons. Firstly, the inconvenience of an irregular grid-point spacing is considerable. Secondly, generalization of the method of characteristics to problems in two spatial dimensions is unattractive. Finally, the discretization of the method introduces approximations, the effect of which is not readily estimated. Liggett and Woolhiser (1969) consider these objections invalid.

\subsubsection{Direct Explicit Methods}

The term explicit refers to those difference methods that advance the solution point by point from one time increment to the next. 


\subsubsection{The Unstable Method}

The simplest method using a rectangular network of points and central spatial differences is unstable, though it has been used by many investigators. The expressions for the wave equations in finite-difference form are, for momentum:

$$
\frac{v_{i}^{j+i}-v_{i}^{j}}{\Delta t}+v_{i}^{j}\left(\frac{v_{i+1}^{j}-v_{i-1}^{j}}{2 \Delta x}\right)+g\left(\frac{h_{i+1}^{j}-h_{i-1}^{j}}{2 \Delta x}+S_{f}-S_{b}\right)+q \frac{v_{i}^{j}}{h_{i}^{j}}=0
$$

and for continuity:

$$
h_{i}^{j}\left(\frac{v_{i+1}^{j}-v_{i-1}^{j}}{2 \Delta x}\right)+v_{i}^{j}\left(\frac{h_{i+1}^{j}-h_{i-1}^{j}}{2 \Delta x}\right)+\frac{h_{i}^{j+1}-h_{i}^{j}}{\Delta t}=q
$$

In these expressions, the subscript $i$ refers to the position along the flow surface and the superscript $j$ refers to the time. The dependent variables, $v$ and $h$, are evaluated at the point $(i, j)$ in this method and enable the unknown values of $v$ and $h$ at $(i, j+1)$ to be found. $S_{f}$ may also vary in both dimensions and are evaluated locally.

The approximation of the difference scheme to the differential equations can be determined by expanding each term in the equations above in a Taylor series, e.g.

$$
\mathrm{h}_{\mathrm{i}}^{\mathrm{j}+1}=\mathrm{h}(\mathrm{x}, \mathrm{t}+\Delta \mathrm{t})=\mathrm{h}+(\Delta \mathrm{t}) \frac{\partial \mathrm{h}}{\partial \mathrm{t}}+\frac{(\Delta \mathrm{t})^{2}}{2} \frac{\partial^{2} \mathrm{~h}}{\partial \mathrm{t}^{2}}+\frac{(\Delta \mathrm{t})^{3}}{6} \frac{\partial^{3} \mathrm{~h}}{\partial \mathrm{t}^{3}}+\mathrm{O}(\Delta \mathrm{t})^{4}
$$

$$
\begin{aligned}
& h_{i+1}^{j}=h(x+\Delta x, t)=h+(\Delta x) \frac{\partial h}{\partial x}+\frac{(\Delta x)^{2}}{2} \frac{\partial^{2} h}{\partial x^{2}}-\frac{(\Delta x)^{3}}{6} \frac{\partial^{3} h}{\partial x^{3}}+O\left(\Delta x^{4}\right) \\
& h_{i-1}^{j}=h(x-\Delta x, t)=h-(\Delta x) \frac{\partial h}{\partial x}+\frac{(\Delta x)^{2}}{2} \frac{\partial^{2} h}{\partial x^{2}}-\frac{(\Delta x)^{3}}{6} \frac{\partial^{3} h}{\partial x^{3}}+O\left(\Delta x^{4}\right)
\end{aligned}
$$

in which, for example, $\mathrm{O}\left(\Delta \mathrm{x}^{4}\right)$ denotes terms containing fourth and higher powers of $\Delta \mathbf{x}$. Expansions similar to these are also obtained for the corresponding $\mathrm{v}$ terms. 
Substitution into the difference equations results in

$$
\frac{\partial \mathrm{v}}{\partial \mathrm{t}}+\frac{\Delta \mathrm{t}}{2} \frac{\partial^{2} \mathrm{v}}{\partial \mathrm{t}^{2}}+\mathrm{O}\left(\Delta \mathrm{t}^{2}\right)+\mathrm{v}\left(\frac{\partial \mathrm{v}}{\partial \mathrm{x}}+\mathrm{O}\left(\Delta \mathrm{x}^{2}\right)\right)+\mathrm{g}\left(\frac{\partial \mathrm{h}}{\partial \mathrm{x}}+\mathrm{S}_{\mathrm{f}}-\mathrm{S}_{\mathrm{b}}+\mathrm{O}(\Delta \mathrm{x})^{2}\right)+\frac{\mathrm{qv}}{\mathrm{h}}=0
$$

and,

$$
h\left(\frac{\partial v}{\partial x}+O\left(\Delta x^{2}\right)\right)+v\left(\frac{\partial h}{\partial x}+O\left(\Delta x^{2}\right)\right)+\frac{\partial h}{\partial t}+\frac{\Delta t}{2} \frac{\partial^{2} h}{\partial t^{2}}+O\left(\Delta t^{2}\right)=q
$$

If $\Delta t=\gamma \Delta \mathrm{x}$ is selected as the relationship between time and distance mesh intervals, in which $\gamma$ is a constant, and $\Delta \mathrm{x}$ is allowed to approach zero, then the two equations above approach

$$
\frac{\partial v}{\partial t}+v \cdot \frac{\partial v}{\partial x}+g\left(\frac{\partial h}{\partial x}+S_{f}-S_{b}\right)+\frac{q v}{h}+O(\Delta x)=0
$$

and,

$$
\mathrm{h} \cdot \frac{\partial \mathrm{v}}{\partial \mathrm{x}}+\mathrm{v} \cdot \frac{\partial \mathrm{h}}{\partial \mathrm{x}}+\frac{\partial \mathrm{h}}{\partial \mathrm{t}}+\mathrm{O}(\Delta \mathrm{x})=\mathrm{q}
$$

Thus the difference scheme approximates the differential equations to the first order in this instance. (The approximation could be made second order by specifying the relationship between the mesh intervals $\Delta t=\gamma \cdot \Delta x^{2}$.) Though this scheme approximates the wave equations as $\Delta x$ tends to zero, the solution of the difference equations does not converge to the solution of the partial differential equations. This is because this scheme lacks the additional requirement of stability (Liggett and Woolhiser, 1967b).

Precise and rigorous stability criteria cannot be found for non-linear equations. The statement that the method is unstable refers to its instability in the limit as $\Delta \mathrm{x}=\Delta \mathrm{t} / \gamma$ tends to zero, where the solution should converge to the exact solution. Most investigators have recognised the Courant condition

$$
\frac{\Delta \mathrm{t}}{\Delta \mathrm{x}}(|\mathrm{v}|+\mathrm{c}) \leq 1
$$

as being necessary, though not sufficient, for the stability of an explicit difference scheme. Satisfying this condition does not guarantee stability - this is the case with the unstable method. Some investigators have improved the stability of this difference scheme, for at least part of the solution, by evaluating some of the terms of the momentum equation at the advance point $(i, j+1)$. However, this is at a cost of decreased accuracy (Terzidis and Strelkoff, 1965). Liggett and Woolhiser (1967b) conclude that the unstable method is unsatisfactory for even rough and approximate calculations. 


\subsubsection{Diffusing Method}

The difference scheme for this method is, for momentum:

$$
\frac{v_{i}^{j+i}-\frac{1}{2}\left(v_{i+1}^{j}+v_{i-1}^{j}\right)}{\Delta t}+v_{i}^{j}\left(\frac{v_{i+1}^{j}-v_{i-1}^{j}}{2 \Delta x}\right)+g\left(\frac{h_{i+1}^{j}-h_{i-1}^{j}}{2 \Delta x}+S_{f}-S_{b}\right)+\frac{q v_{i}^{j}}{h_{i}^{j}}=0
$$

and for continuity:

$$
h_{i}^{j}\left(\frac{v_{i+1}^{j}-v_{i-1}^{j}}{2 \Delta x}\right)+v_{i}^{j}\left(\frac{h_{i+1}^{j}-h_{i-1}^{j}}{2 \Delta x}\right)+\frac{h_{i}^{j+1}-\frac{1}{2}\left(h_{i+1}^{j}+h_{i-1}^{j}\right)}{\Delta t}=q
$$

As in the unstable method, the dependent variables are evaluated at the central point $(i, j)$. This method employs central and forward differences.

Other variants of the diffusing method have been used. Isaacson, et al. (1958) wrote the $\mathrm{x}$ derivatives in the conservation form:

$$
\frac{\partial(u h)}{\partial x} \approx \frac{(u h)_{i+1}^{j}-(u h){ }_{i-1}^{j}}{2 \Delta x}
$$

but in any variant of the method the time derivatives used must be as they appear in the above equations.

If the terms in these equations are expanded in a Taylor series, the equations obtained are:

$$
\frac{\partial v}{\partial t}+\frac{(\Delta x)^{2}}{2 \Delta t} \cdot \frac{\partial^{2} v}{\partial x^{2}}+v \cdot \frac{\partial v}{\partial x}+g\left(\frac{\partial h}{\partial x}+S_{f}-S_{b}\right)+\frac{q v}{h}+O\left(\Delta x^{2}, \Delta t\right)=0
$$

and,

$$
h \cdot \frac{\partial v}{\partial x}+v \frac{\partial h}{\partial x}+\frac{\partial h}{\partial t}+\frac{(\Delta x)^{2}}{2 \Delta t} \cdot \frac{\partial^{2} h}{\partial x^{2}}+O\left(\Delta x^{2}, \Delta t\right)=q
$$

If the relationship between the mesh intervals is $\Delta t=\gamma \cdot \Delta x^{2}$, the difference scheme approximates a system of differential equations different from the wave equations. If $\Delta t$ is taken to be very small in relation to $\Delta x$, the second term in the first equation and the fourth term in the second of the equations above may assume considerable importance.

If the Courant condition is satisfied, the diffusing method is theoretically stable, but the solution to this system of difference equations may not converge to the solution of the differential equations. 


\subsubsection{Leap-frog Method}

In the leap-frog method, the central-difference scheme is, for momentum:

$$
\frac{v_{i}^{j+1}-v_{i}^{j-1}}{2 \Delta t}+v_{i}^{j}\left(\frac{v_{i+1}^{j}-v_{i-1}^{j}}{2 \Delta x}\right)+g\left(\frac{h_{i+1}^{j}-h_{i-1}^{j}}{2 \Delta x}+S_{f}-S_{b}\right)+\frac{q v_{i}^{j}}{h_{i}^{j}}=0
$$

and for continuity:

$$
h_{i}^{j}\left(\frac{v_{i+1}^{j}-v_{i-1}^{j}}{2 \Delta x}\right)+v_{i}^{j}\left(\frac{h_{i+1}^{j}-h_{i-1}^{j}}{2 \Delta x}\right)+\frac{h_{i}^{j+1}-h_{i}^{j-1}}{2 \Delta t}=q
$$

The equations are formulated about the central point $(i, j)$. This scheme approximates the wave equations to the second order, $\mathrm{O}\left(\Delta \mathrm{x}^{2}\right)$, and is stable if the Courant condition is satisfied. The leap-frog method assumes that the solution at two times (rows of points) are known and the solution is then projected to the third row. Thus there is a starting problem with the use of this method, which is overcome in the application of the Lax-Wendroff two-step method, discussed below.

\subsubsection{Lax-Wendroff Methods}

\section{The two-step method}

This is a two-cycle scheme which first uses the difference scheme of the diffusing method to advance the solution one row and then applies the leap-frog scheme to the second row. The result is a method with a truncation error of $(\Delta x)^{3}$, i.e. a second-order approximation, $\mathrm{O}\left(\Delta \mathrm{x}^{2}\right)$, which should exhibit positive damping of short wave disturbances (Richtmyer, 1962).

\section{The single-step method}

This method, described by Liggett and Woolhiser (1969), is analogous to that used by Houghton and Kasahara (1968) for an atmospheric problem.

The formulation of this scheme is rather complex and is best handled using dimensionless terms and matrix notation. The difference scheme is constructed by expanding $W(x, t+\Delta t)$, where $W=\left(\begin{array}{c}v h \\ h\end{array}\right)$ in a Taylor series:

$$
\mathrm{W}(\mathrm{x}, \mathrm{t}+\Delta \mathrm{t})=\mathrm{W}(\mathrm{x}, \mathrm{t})+\Delta \mathrm{t} \cdot \frac{\partial \mathrm{W}}{\partial \mathrm{t}}+\frac{1}{2}(\Delta \mathrm{t})^{2} \cdot \frac{\partial^{2} \mathrm{~W}}{\partial \mathrm{t}^{2}}+\mathrm{O}\left(\Delta \mathrm{t}^{3}\right)
$$


and substituting in the expressions for $\partial \mathrm{W} / \partial \mathrm{t}$ and $\partial^{2} \mathrm{~W} / \partial \mathrm{t}^{2}$ from the wave equations in their dimensionless form. The matrix form of the resulting finite difference scheme is developed by Liggett and Woolhiser (1969) and given finally as:

$$
\begin{aligned}
& W_{i}^{j+1}=W_{i}^{j}-\frac{\Delta t}{\Delta x}\left(\Delta G_{i}^{j}+\Delta x \cdot K_{i}^{j}\right)+\frac{1}{2}\left(\frac{\Delta t}{\Delta x}\right)^{2} . \\
& \left(A_{i+\frac{1}{2}}{ }^{j}\left(\Delta G_{i+\frac{1}{2}}{ }^{j}+\Delta x \cdot K_{i+\frac{1}{2}}{ }^{j}\right)-A_{i-\frac{1}{2}}^{j}\left(\Delta G_{i-\frac{1}{2}}^{j}+\Delta x \cdot K_{i-\frac{1}{2}}^{j}\right)-Q_{i}^{j}\right)
\end{aligned}
$$

in which each term $(A, G, K, Q)$ is a vector or matrix of difference terms in dimensionless form.

Of all explicit difference schemes, Woolhiser (1969) recommends the single-step Lax-Wendroff method. Perturbations in depth profiles obtained from other explicit methods are successfully damped out using this method.

\section{The implicit method}

The term implicit refers to a difference method due to Crank and Nicolson (1947) in which the solution along a row of grid points is obtained from the simultaneous solution of a set of difference equations.

The central difference scheme may be written for momentum:

$$
\begin{aligned}
& \frac{v_{i}^{j+1}-v_{i}^{j}}{\Delta t}+\tilde{v}\left(\frac{\left(v_{i+1}^{j}-v_{i-1}^{j}\right)+\left(v_{i+1}^{j+1}-v_{i-1}^{j+1}\right)}{4 \Delta x}\right) \\
& +g\left(\frac{\left(h_{i+1}^{j}-h_{i-1}^{j}\right)+\left(h_{i+1}^{j+1}-h_{i-1}^{j+1}\right)}{4 \Delta x}+S_{f}-S_{b}\right)+q \cdot \frac{\widetilde{v}}{\widetilde{h}}=0
\end{aligned}
$$

and for continuity:

$$
\begin{gathered}
\tilde{h}\left(\frac{\left(v_{i+1}^{j}-v_{i-1}^{j}\right)+\left(v_{i+1}^{j+1}-v_{i-1}^{j+1}\right)}{4 \Delta x}\right)+\tilde{v}\left(\frac{\left(h_{i+1}^{j}-h_{i-1}^{j}\right)+\left(h_{i+1}^{j+1}-h_{i-1}^{j+i}\right)}{4 \Delta x}\right) \\
+\frac{h_{i}^{j+1}-h_{i}^{j}}{\Delta t}=q
\end{gathered}
$$


These equations are written for evaluation of the variables at the point $(i, j+1 / 2)$, using central differences. In these equations

$$
\widetilde{v}=\frac{1}{2}\left(\begin{array}{c}
\bar{v}_{i}^{j+1}+v_{i}^{j}
\end{array}\right) \text { and } \tilde{h}=\frac{1}{2}\left(\bar{h}_{i}^{j+1}+h_{i}^{j}\right)
$$

where:

$\overline{\mathrm{v}}^{\mathrm{j}+1}=\mathrm{v}^{\mathrm{j}+1}$ and $\overline{\mathrm{h}}^{\mathrm{j}+1}=\mathrm{h}^{\mathrm{j}+1}$ in the products $\widetilde{\mathrm{v}} \cdot \mathrm{v}^{\mathrm{j}}, \tilde{\mathrm{h}} \cdot \mathrm{v}^{\mathrm{j}}$ and $\widetilde{\mathrm{v}} \cdot \mathrm{h}^{\mathrm{j}}$.

In the products $\tilde{\mathrm{v}} \cdot \mathrm{v}^{\mathrm{j}+1}, \tilde{\mathrm{h}} \cdot \mathrm{v}^{\mathrm{j}+1}$ and $\tilde{\mathrm{v}} \cdot \mathrm{h}^{\mathrm{j+1}}, \overline{\mathrm{v}}^{\mathrm{j}+1}=\mathrm{v}^{\mathrm{j}}$ and $\overline{\mathrm{h}}^{\mathrm{j}+1}=\mathrm{h}^{\mathrm{j}}$, for the initial advancement; and $\bar{v}^{j+1}=v^{j+1}$ and $\bar{h}^{j+1}=h^{j+1}$ for subsequent iterations.

The difference scheme for this method represents two equations in each of $(\mathrm{N}-2)$ interior points in the unknowns $\mathrm{v}^{\mathrm{j}+1}$ and $\mathrm{h}_{\mathrm{i}}^{\mathrm{j}+1}$. These equations form a closed system if it is assumed that the solution is known at the boundaries $i=1$ and $\mathrm{i}=\mathrm{N}$ (where the number of mesh intervals, $\Delta \mathrm{x}$, is $\mathrm{N}-1$ ). Centering the variables $\mathrm{v}$ and $\mathrm{h}$ according to the expressions above for $\tilde{\mathrm{v}}$ and $\tilde{\mathrm{h}}$ facilitates the solution of the system of $2 \mathrm{~N}-4$ equations. The solution at the $(j+1)$ th row is then obtained by an iterative procedure, which terminates when the new values of $\mathrm{v}_{\mathrm{i}}^{\mathrm{j}+1}$ and $\mathrm{h}_{\mathrm{i}}^{\mathrm{j}+1}$ are acceptably close to the values obtained in the previous iteration.

The implicit scheme approximates the partial differential wave equations to the second order and the ratio $\Delta t / \Delta x$ is not governed by the Courant condition. Some investigators have considered this fact to be a substantial advantage of the method, but Liggett and Woolhiser (1967b) found that increasing the time interval to an amount which is approximately double the Courant condition resulted in inaccuracy and problems of stability. Making both $\Delta t$ and $\Delta x$ large results in shorter computer running time but leads to a decrease in accuracy, as was found by Abbott and Ionescu (1967). The implicit method is held by Liggett and Woolhiser (1967b) to be advantageous in situations where stability is not a factor, as in some river problems, though Amein (1968) considers the method to have no major advantage over explicit methods in regard to accuracy of results or computer running time. Vreugdenhil (1968) reported a large distortion resulting from the use of the central implicit method, which may lead to the rejection of implicit methods in spite of their unconditional stability.

\subsection{Comparative Studies}

The final choice of a difference scheme for nonlinear wave equations should be based on experimental studies of the effects of instability and flexibility of the solutions. Liggett and Woolhiser (1967b) in their comparative experimental 
studies found the characteristic method most accurate and not subject to problems of convergence. All the other methods, including the implicit method, exhibited convergence problems at certain parameter values, albeit these parameters were associated with a physically stable problem. Instabilities often originated at or near the boundaries, possibly in regions of large curvature of depth and velocity. In all their experiments, some irregularity occurred in the rising hydrographs at the time when the upstream boundary condition (based on symmetry, i.e. $h(x)=h(-x)$ and $v(x)=-v(-x))$ was felt at the outfall.

With the unstable method, the steady-state profiles broke up into long waves with growing amplitudes. They found that reducing the time increment, $\Delta t$, decreased the rate of growth of the oscillations, but did not prevent their occurrence. They found the diffusing method to be inflexible, with the oscillations growing to the point of dominating the desired components in the computation, though these disturbances could be smoothed out by a filtering scheme. Their findings in regard to the use of the two-step Lax-Wendroff and Leap-frog schemes were similar to those for the diffusing method. They were also able to devise an effective filtering scheme for the Lax-Wendroff method. The use of the single-step Lax-Wendroff method produced no oscillations and gave results that agreed closely with those obtained using the characteristic method.

Liggett and Woolhiser (1969), after analyzing their difference schemes as suggested by Vreugdenhil (1968) concluded finally that carefully chosen explicit methods can indeed be used for numerical solution of the shallow-water equation but the error of approximation is likely to be greater than that associated with the method of characteristics. Also schemes (which they) classified as stable but inflexible can be made useful by properly averaging the resistance term. The linearly stable difference schemes that they investigated failed when the nonlinear terms in the wave equations assumed importance in the computation at certain parameter values.

According to Vreugdenhil(1968) the main criterion in comparing difference methods is an economic one: which method gives results with a specified accuracy involving least work? He showed that some methods, rejected by Liggett and Woolhiser (1967b), become satisfactory when the difference schemes are modified slightly. Holsters (1961) had found hydraulic friction to be the cause of instability in his oceanographic research and Vreugdenhil (1966) determined that the effect could be either stabilizing or destabilizing, depending on the type of the difference method used.

If: $\quad \frac{\partial v}{\partial t}+v \frac{\partial v}{\partial x}+g\left(\frac{\partial h}{\partial x}+S_{f}-S_{b}\right)+\frac{q v}{h}=0$

is written in difference form as 


$$
\begin{gathered}
\frac{v_{i}^{j+1}-v_{i}^{j}}{\Delta t}+v_{i}^{j}\left(\frac{v_{i+1}^{j}-v_{i-1}^{j}}{2 \Delta x}\right)+g\left(\frac{h_{i+1}^{j}-h_{i-1}^{j}}{2 \Delta x}+S_{f}-S_{b}\right) \\
+\frac{q^{\cdot} \cdot v_{i}^{j}}{h_{i}^{j}}-\alpha \cdot \frac{v_{i+1}^{j}-2 v_{i}^{j}+v_{i-1}^{j}}{2 \Delta t}=0
\end{gathered}
$$

then, with $\alpha=1$ the momentum difference equation for the diffusing method is obtained; and with $\alpha=0$, the momentum difference equation for the unstable method results. This equation will also govern the propagation of a disturbance, $\varepsilon_{\mathrm{i}}^{\mathrm{j}}$ Richtmyer (1962) investigated the effect of such a disturbance in a stability analysis.

By substituting the expression (Vreugdenhil, 1968):

in which

$$
\varepsilon_{\mathrm{i}}^{\mathrm{m}}=\varepsilon_{0} \rho^{\mathrm{m}} \exp (\mathrm{i} \mathrm{j} \sigma \Delta \mathrm{x})
$$

$$
\begin{aligned}
\mathrm{j}= & \text { the imaginary unit, } \\
\sigma= & \text { the wave number of the disturbance }(2 \pi / \text { (wave length)) } \\
& \text { and } \\
\rho= & \text { the amplification factor per time interval, }
\end{aligned}
$$

it is found that

$$
\rho=1-\mathrm{j} \mu \sin \theta-\mathrm{r} \cdot \Delta \mathrm{t}+\alpha(\cos \theta-1)
$$

where:

$$
\begin{aligned}
\mu & =\mathrm{v}_{\mathrm{i}}^{\mathrm{j}} \cdot \frac{\Delta \mathrm{t}}{\Delta \mathrm{x}} \\
\theta & =\sigma \cdot \Delta \mathrm{x}, \text { and } \\
\mathrm{r} & =\text { the coefficient of } \mathrm{v}_{\mathrm{i}}^{\mathrm{j}} \text { in the friction term } \mathrm{g} \mathrm{S}_{\mathrm{f}} .
\end{aligned}
$$

Given $\Delta x$ and $\Delta t$, the disturbance grows exponentially if $|\rho|>1$. This occurred in the schemes of Liggett and Woolhiser (1967b). In a useful difference method this exponential growth should not occur; for this, $|\rho|<1$ is a necessary condition. This implies,

(a) for the diffusing method $\alpha<1-1 / 2 \mathrm{r} \cdot \Delta \mathrm{t}$ and $\mu<\alpha$, so that $\alpha$ should be $<1$.

(b) for the two-step Lax-Wendroff method

$$
\alpha<1 / 2-1 / 2 \mathrm{r} \Delta \mathrm{t} \text { and } \mu<\alpha^{1 / 2},
$$


with $\alpha$ applied only to the first step.

The leap-frog method can be made stable by using an average for the resistance term (Holsters, 1961; Vreugdenhil, 1966), i.e. $v_{i}^{j}$ in the resistance term, $\mathrm{gS}_{\mathrm{f}}$ is replaced by $\frac{1}{2}\left(\begin{array}{c}v_{i}^{j+1}+v_{i}^{j-1} \\ i\end{array}\right)$. The stability criterion is then found to $b e \mu<1$.

The need for a restriction on the value of the time increment, $\Delta t$, in addition to that imposed by the Courant condition, was recognized by Fenzl (1965). He found that values of $\Delta t$ which met the Courant condition may not be small enough to prevent the initiation of oscillations in the rising limb of the outfall hydrograph after a lapse of some time, but before equilibrium flow was reached.

Vreugdenhil (1968) ultimately based his choice of difference scheme for a particular application on the amount of work (the number of computer operations) for a specified accuracy, involved in using the various methods available. He investigated accuracy using a method introduced by Leendertse (1967), who proposed an error propagation factor

$$
T=\rho^{2 \pi / \mu \theta} \exp (2 \pi j)
$$

as a measure of accuracy of the difference solution. The modulus of $T$ denotes the damping and the argument, divided by $2 \pi$, gives the deviation in velocity of propagation caused by the difference method employed. Vreugdenhil, (1968) published charts showing accuracy (damping and relative velocity of propagation) and the amount of work involved in using the various difference schemes. Depending on the choice of the intervals $\Delta \mathrm{x}$ and $\Delta \mathrm{t}$, one or another method may be found most economical. One trend which became apparent from his studies was the large distortion caused by the central-implicit method referred to already.

Harbaugh (1967) found the oscillatory behavior of explicit schemes quite pronounced when using central-difference approximations, though this behavior was reduced with the use of smaller time increments, $\Delta t$. He also reported that reducing the rainfall intensity had a stabilizing effect on the solution. When the oscillations became troublesome, for instance in determining time to equilibrium, he used backward differences for the derivatives with respect to $\mathrm{x}$ and obtained smooth hydrographs showing no instability. However, it seems that resort even to this subterfuge is no panacea for the ills of finite difference methods. In an analysis of stability, Liggett and Woolhiser (1969) show that a backwarddifference scheme may be satisfactory for some subcritical flows, but is not suitable for subcritical flow in general. This conclusion is obvious from physical considerations, since the backward-difference scheme alters the differential equations so that disturbances cannot propagate upstream.

Schaake (1965) executed his explicit scheme computations in a downstream direction, using central differences when the flow was subcritical and backward differences when it was supercritical. He was able to ensure stability 
by using a small time increment (Schaake, 1971). Backward differences were used also by Abdel-Razaq et al. (1967) in their study of surface runoff.

Some explicit difference schemes, in which instabilities are generated, have filtered them out at each time increment to obtain a stable solution. Also, rectangular space-time grids may be used, in which depth is defined at even values and discharge at odd values of $i$ and j. Fenzl (1965) experienced some difficulty with the use of a rectangular grid when the flow was subcritical and a downstream boundary condition of critical-depth was imposed. Under these circumstances he found that continuity was not satisfied from one grid point to the next in the $x$-direction. This problem was overcome to some extent by using a staggered solution grid, on which points at time $t+\Delta t$ were offset from those at time, t. Though most investigators appear to define depth and discharge (velocity) at the same points on a rectangular grid, and not offset from one another in any way, the grids employed by Fenzl (1965) may have merit. There is a possible reduction of errors with the employment of halved space and time increments, through the device of staggering solution points on the space-time plane, while not increasing materially the computations involved.

The literature indicates considerable differences of opinion regarding the usefulness of the various difference schemes. Both explicit and implicit schemes were applied by the present writers to the solution of the dynamic wave equations and the hydrographs of runoff obtained thereby compared with those found from the physical model discussed in the next chapter. Finite difference schemes are described below, together with the difficulties experienced in their application.

Our numerical models were designed to reproduce flow for the surface length, width and slope used in our laboratory model; as were also the rain rates and durations, and the duration of runoff. The flow surface in the numerical model was assumed to be dry at the start of a computer run, i.e. depths and velocities were initially zero over the entire flow surface. For this work infiltration was ignored.

\subsection{Generalized Numerical Model}

In this section we discuss the processes and procedures used in our experimental and numerical work in Durban in the late 1960's and early 1970's.

\subsubsection{Flow Conditions}

Possible conditions of flow over the surface were subcritical or supercritical laminar flow and subcritical or supercritical turbulent flow, depending on the values of the Froude and Reynolds numbers obtaining. For the velocities and depths, the Reynolds number, $\operatorname{Re}=\frac{v \cdot h}{v}$, was always very much less than 
500 , the value usually accepted as the transition point from laminar to turbulent flow in open-channel flow (Chow, 1959; Webber, 1965). The flows studied should, therefore, be considered to be laminar. However, due to the impact of rain on the shallow flowing water, considerable turbulence was induced in the flow (Woo and Brater, 1962; Grace and Eagleson, 1966). This effect increased the depth of flow and reduced its velocity and may therefore be accounted for by an increase in the friction coefficient during precipitation (Woo and Brater, 1962); or a downward adjustment of the transitional Reynolds number (TRANR) at which the flow is considered to change from laminar to turbulent may be made. We adopted the latter course, involving turbulent flow at low Reynolds numbers, though it does not appear to have been used by other investigators. After cessation of rain the computed flow was made to be laminar.

In central-difference explicit and implicit schemes, no differentiation is necessary between subcritical and supercritical flows, except at the overfall point where, if the Froude number (equation 5.5) is found to be less than unity, depth and velocity may be recalculated assuming a Froude number equal to unity, the condition for critical flow. Critical flow conditions were applied in some of the original computer runs using the explicit scheme. This was not done in the case of the implicit scheme, due to the necessity of calculating several values of depth and velocity for the simultaneous solution of the equations by iteration such a procedure would consume considerable computer time, without materially affecting the results (Morgali and Linsley, 1965).

\subsubsection{Friction Factor and Surface Rugosity}

The Darcy-Weisbach resistance term, $\mathrm{S}_{\mathrm{f}}$ was adopted

$$
\mathrm{S}_{\mathrm{f}}=\frac{\mathrm{f} \cdot \mathrm{v}^{2}}{8 \mathrm{gh}}
$$

with the friction coefficient, $\mathrm{f}$, calculated

- from $f=24 / \operatorname{Re}$, when the flow was laminar and Reynolds number, $\mathrm{Re}$, was less than the transitional Reynolds number; and

- from the Colebrook-White formula

$$
\frac{1}{\sqrt{\mathrm{f}}}=-2 \log _{10}\left(\frac{\mathrm{DR}}{14.8 \mathrm{~h}}+\frac{0.6275}{\operatorname{Re} \cdot \sqrt{\mathrm{f}}}\right)
$$

when the flow was turbulent and Reynolds number was greater than the transitional Reynolds number. In this formula

$$
\begin{aligned}
D R & =\text { surface rugosity } \\
h & =\text { depth of flow. }
\end{aligned}
$$


The Colebrook-White $f$ was computed using the explicit formulation due to Wood (1966), requiring only a direct calculation without iteration and resulting in a considerable saving in computer time. This formulation is:

$$
f=0.094\left(\frac{D R}{4 h}\right)^{0.225}+0.53\left(\frac{D R}{4 h}\right)+\frac{88\left(\frac{D R}{4 h}\right)^{0.44}}{\operatorname{Re}^{1.62}\left(\frac{D R}{4 h}\right)^{0.134}}
$$

and was used by Schreiber (1970) in his study of overland flow. The very small depths obtaining in the early stages of rain on the initially dry flow-surface result in excessively high values of the friction factor, $f$, being calculated. To obviate this possibility, a maximum value of 24 was imposed for the friction coefficient, roughly corresponding to laminar flow conditions at a Reynolds number equal to unity. The same difficulty was experienced by Abdel-Razaq et al. (1967) and was overcome in a similar manner.

The rugosity of the flow surface of the physical model was not determined and several computer runs were made to observe the effect of this parameter on the computed hydrograph. At small depths the effect of boundary roughness is much greater than at larger depths (Woo and Brater, 1962). Ideally, the friction factor should be optimized to obtain good correspondence between computed and laboratory runoff hydrographs.

Values of the friction factor were checked, and recalculated if necessary, each time a velocity was computed. The same formulation was used in all the schemes studied and, since the calculation was repeated frequently, it was programmed as a subroutine to be used in the main program when required. This subroutine examined the current value of the friction factor on the basis of whether or not the value of the Reynolds number had changed materially since the friction coefficient was last calculated. When the current value of Reynolds number was 10 or less, the friction factor was recalculated if the Reynolds number had changed in value by 1 or more. It was recalculated if the Reynolds number had changed by 10 or more, between values of 10 and 200; and if the Reynolds number had changed by 100 or more, when the current value exceeded 200. (The largest value of Reynolds number that we obtained was of the order of 100.) When the Reynolds number was unity or less, the friction factor was taken to be 24 , as was done if its calculated value exceeded this figure at any stage. The effect of this process on the computed hydrograph in relation to the anomalous hump is discussed later.

\subsubsection{Starting Time Increment}

With a time increment of $0.1 \mathrm{~s}$, the initial values of computed velocity were rather high and they oscillated considerably over the first second of rain before becoming stable. It was found that reduction of the time increment initially to 
0.01 s produced no immediate instability and gave values of velocity that seemed reasonable.

The difference schemes used were, accordingly, programmed to solve the dynamic wave equations with a time increment of $0.01 \mathrm{~s}$ during the first second of precipitation and thereafter to revert to the time interval chosen for the particular scheme and computer run in progress.

\subsubsection{Rectangular Network}

A staggered network of solution points with depths computed at points $\Delta \mathrm{x}$ and $\Delta t$ apart on the $x$ - $t$ plane and velocities computed at intermediate points at $\frac{\Delta \mathrm{x}}{2}$ and $\frac{\Delta \mathrm{t}}{2}$ intervals from the depth solution points was chosen. The arrangement of these solution points is shown in Figure 5.1.

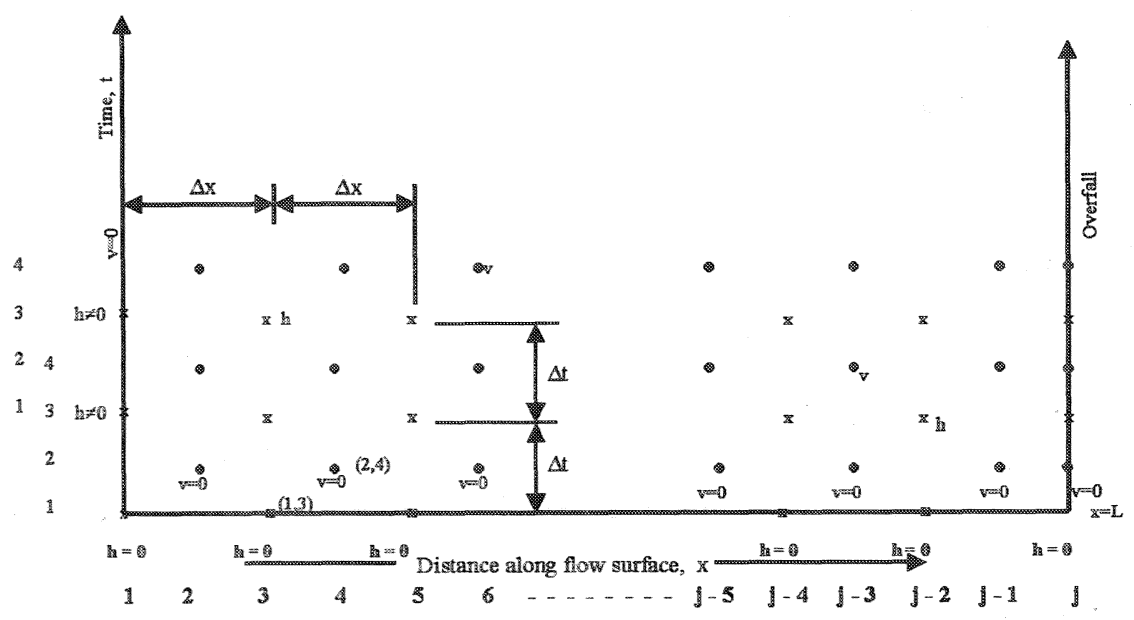

Figure 5.1 Rectangular network solution points $x-t$ plane.

\subsubsection{Solution Procedure}

Depths were calculated from the continuity equation, along the third row and velocities from the momentum equation, along the fourth row, initially assuming that depths along the first row at $\mathrm{t}=0$ and velocities along the second row at $\mathrm{t}=\frac{\Delta \mathrm{t}}{2}$ were zero. Those computed values of depth and velocity were then used as first and second rows, respectively, to calculate the values in the next two rows, viz. the new third and fourth rows, at times $4 \cdot \Delta t$ and $5 \cdot \Delta t$ respectively. The computation proceeded in this manner until some time after the cessation of rain, when the flow was reduced to negligible proportions. 
Both depths and velocities were calculated at the downstream overfall at time intervals $\frac{\Delta \mathrm{t}}{2}$ apart. The product of the depth computed at this point on row 3 , the average of the velocities at this point on rows 2 and 4, and the constant width of the flow surface, was used to construct the computed runoff hydrograph.

\subsection{Testing the Numerical Model}

While the crucial test of the model is the correspondence of the runoff hydrographs with those obtained from the laboratory model, careful testing of the mathematical models was undertaken during the first few seconds of rain. Adjustments to the programs were made during this stage when necessary.

\subsubsection{Physical Parameters}

Acceleration due to gravity $\left(\mathrm{m} / \mathrm{s}^{2}\right)$ was determined from (Flügge, 1962):

$$
g=9.7803\left(1+0.00524 \sin ^{2} \ddot{o}\right)(1-0.000000315 h)
$$

in which:

$$
\begin{aligned}
& \mathrm{h}=\text { height above sea level (m), and } \\
& \phi=\text { latitude, }
\end{aligned}
$$

For the latitude of Durban $\left(30^{\circ} \mathrm{S}\right)$ and the height of the university (approximately 70 meters) above sea level, gravity equals $9793 \mathrm{~mm} / \mathrm{s}^{5}$. The value of 1.086 $\mathrm{mm}^{2} / \mathrm{s}$ was taken to be the kinematic viscosity of water at $17^{\circ} \mathrm{C}$ (Massey, 1968), the average temperature of the water in the tests.

\subsubsection{Direct Explicit Schemes}

Two explicit difference schemes were examined:

1. central spatial differences and

2. central and backward spatial differences.

\subsubsection{Unstable Central Difference Scheme with Stabilizing Factor}

In the formulation of these equations, (after Woolhiser and Liggett, 1967b; Vreugdenhil, 1968), care was taken to ensure that no expressions rightly belonging to a diffusing scheme were used in this unstable scheme. This precaution was necessary to examine the influence of Vreugdenhil's factor, $\alpha$, on the stability of the scheme. The difference equations for the determination of depths and velocities at interior points on the $x$-t plane used the patterns of grid points of the rectangular network. 
Continuity: $\quad \mathrm{h}_{3, \mathrm{~m}}=\frac{\mathrm{A}}{\mathrm{B}}$

where:

$$
\begin{gathered}
A=4\left(\mathrm{q} \cdot \Delta \mathrm{x}+\mathrm{h}_{1, \mathrm{~m}} \cdot \frac{\Delta \mathrm{x}}{\Delta \mathrm{t}}\right)-\left(\mathrm{v}_{2, \mathrm{~m}+1}+\mathrm{v}_{2, \mathrm{~m}-1}\right) \cdot\left(\mathrm{h}_{1, \mathrm{~m}+2}-\mathrm{h}_{1, \mathrm{~m}-2}\right) \\
-2 \cdot \mathrm{h}_{1, \mathrm{~m}} \cdot\left(\mathrm{v}_{2, \mathrm{~m}+1}-\mathrm{v}_{2, \mathrm{~m}-1}\right)
\end{gathered}
$$

and

$$
\mathrm{B}=2\left(\mathrm{v}_{2, \mathrm{~m}+1}-\mathrm{v}_{2, \mathrm{~m}-1}\right)+4 \cdot \frac{\Delta \mathrm{x}}{\Delta \mathrm{t}}
$$

Momentum:

$$
\mathrm{v}_{4, \mathrm{n}}=\frac{\mathrm{C}}{\mathrm{D}}
$$

where:

$$
\begin{gathered}
C=v_{2, n}\left(4\left(\frac{\Delta x}{\Delta t}-\frac{q \cdot \Delta x}{h_{3, n+1}+h_{3, n-1}}\right)-v_{2, n+2}+v_{2, n-2}\right)+ \\
4 g\left(S \cdot \Delta x-h_{3, n+1}+h_{3, n-1}\right)+2 \cdot \alpha \cdot \frac{\Delta x}{\Delta t}\left(v_{2, n+2}-2 \cdot v_{2, n}+v_{2, n-2}\right) \\
D=4 \cdot \frac{\Delta x}{\Delta t}+v_{2, n+2}-v_{2, n-2}+\frac{\Delta x}{h_{3, n+1}+h_{3, n-1}}\left(f \cdot v_{2, n}+4 \cdot q\right)
\end{gathered}
$$

and $\quad \alpha=$ the stabilizing factor used by Vreugdenhil (1968).

For the upstream boundary, the velocity was always zero and the continuity equation was:

$$
\frac{h_{1,3}+h_{3,1}}{2} \cdot \frac{v_{a}}{\Delta x}+v_{2,2} \frac{\left(h_{1,3}-h_{1,1}\right)}{\Delta x}+\frac{h_{a}-h_{b}}{\Delta t}=q
$$

where

and

$$
\begin{aligned}
& h_{a}=\frac{3}{8} h_{3,1}+\frac{3}{4} h_{3,3}-\frac{1}{8} h_{3,5} \\
& h_{b}=\frac{3}{8} h_{1,1}+\frac{3}{4} h_{1,3}-\frac{1}{8} h_{1,5}
\end{aligned}
$$

$$
\mathrm{v}_{\mathrm{a}}=\frac{3}{8} \mathrm{v}_{2,2}+\frac{3}{4} \mathrm{v}_{2,4}-\frac{1}{8} \mathrm{v}_{2,6}
$$

from a parabolic interpolation through three grid solution points. This leads to

$$
\mathrm{h}_{3,1}=\frac{\mathrm{E}}{\mathrm{F}}
$$

where: 
and

$$
E=2 \cdot \Delta x\left(\frac{\left(h_{b}-\frac{3}{4} h_{3,3}+\frac{1}{8} h_{3,5}\right)}{\Delta t+q}\right)-h_{1,3} \cdot v_{a}-2 \cdot v_{2,2}\left(h_{1,3}-h_{1,1}\right)
$$

in which $h_{a}$ has been replaced by its expanded form above, since it is dependent, in part, on the value of $h_{3,1}$. The initial calculation of $h_{3,1}$ is in error by a factor of two, if the above equation is used for its determination. The model was, therefore, written to calculate, initially: $h_{3,1}=q \cdot \Delta t$.

For the calculation of velocity at the upstream penultimate solution point, with the momentum equation, get

$$
\mathrm{v}_{4,2}=\frac{\mathrm{G}}{\mathrm{H}}
$$

where:

$$
\begin{aligned}
\mathrm{G}=\mathrm{v}_{2,2}\left(\frac{\Delta \mathrm{x}}{\Delta \mathrm{t}}-\right. & \left.\frac{1}{2} \cdot \mathrm{v}_{\mathrm{a}}-\frac{\mathrm{q} \cdot \Delta \mathrm{x}}{\mathrm{h}_{3,1}+\mathrm{h}_{3,3}}\right)+\mathrm{g}\left(\mathrm{s} \cdot \Delta \mathrm{x}-\mathrm{h}_{3,3}+\mathrm{h}_{3,1}\right) \\
& +\frac{\alpha}{2} \cdot \frac{\Delta \mathrm{x}}{\Delta \mathrm{t}}\left(\mathrm{v}_{\mathrm{a}}-2 \cdot \mathrm{v}_{2,2}\right) \\
\mathrm{H}=\frac{\Delta \mathrm{x}}{\Delta \mathrm{t}}+\frac{1}{2} \cdot \mathrm{v}_{\mathrm{a}} & +\frac{\Delta \mathrm{x}}{\mathrm{h}_{3,1}+\mathrm{h}_{3,3}}\left(\frac{\mathrm{f}}{4} \cdot \mathrm{v}_{2,2}+\mathrm{q}\right)
\end{aligned}
$$

and

$$
\mathrm{v}_{\mathrm{a}}=\frac{3}{8} \cdot \mathrm{v}_{2,2}+\frac{3}{4} \cdot \mathrm{v}_{2,4}-\frac{1}{8} \cdot \mathrm{v}_{2,6}
$$

The velocity at the downstream penultimate solution point was determined, using the momentum equation, from

where:

$$
\mathrm{V}_{4, \mathrm{j}-1}=\frac{\mathrm{I}}{\mathrm{J}}
$$

$$
\begin{gathered}
I=v_{2, j-1}\left(\frac{\Delta x}{\Delta t}-\frac{1}{2} \cdot\left(v_{2, j}-v_{a}\right)-\frac{q \cdot \Delta x}{h_{3, j}+h_{3, j-2}}\right)+g\left(S \cdot \Delta x-h_{3, j}+h_{3, j-2}\right) \\
+\frac{\alpha}{2} \cdot \frac{\Delta x}{\Delta t}\left(v_{2, j}-2 \cdot v_{2, j-1}+v_{a}\right) \\
J=\frac{\Delta x}{\Delta t}+\frac{1}{2} \cdot\left(v_{2, j}-v_{a}\right)+\frac{\Delta x}{h_{3, j}+h_{3, j-2}}\left(\frac{f}{4} \cdot v_{2, j-1}+q\right)
\end{gathered}
$$

and 


$$
v_{a}=\frac{3}{8} \cdot v_{2, j-1}+\frac{3}{4} \cdot v_{2, j-3}-\frac{1}{8} \cdot v_{2, j-5}
$$

Finally, the depths and velocities at the downstream boundary were determined from the following equations.

Continuity:

$$
\mathrm{h}_{3, \mathrm{j}}=\frac{\mathrm{K}}{\mathrm{L}}
$$

where:

$$
\begin{aligned}
& \mathrm{K}=\Delta \mathrm{x}\left(\frac{\left(\mathrm{h}_{\mathrm{b}}-\frac{3}{4} \cdot \mathrm{h}_{3, \mathrm{j}-2}+\frac{1}{8} \mathrm{~h}_{3, \mathrm{j}-4}\right)}{\Delta \mathrm{t}+\mathrm{q}}\right)-\frac{1}{2} \cdot \mathrm{h}_{1, \mathrm{j}-2}\left(\mathrm{v}_{2, \mathrm{j}}-\mathrm{v}_{\mathrm{a}}\right)-\mathrm{v}_{2, \mathrm{j}-1}\left(\mathrm{~h}_{1, \mathrm{j}}-\mathrm{h}_{1, \mathrm{j}-2}\right) \\
& \mathrm{L}=\frac{3}{8} \cdot \frac{\Delta \mathrm{x}}{\Delta \mathrm{t}}+\frac{1}{2}\left(\mathrm{v}_{2, \mathrm{j}}-\mathrm{v}_{\mathrm{a}}\right) \\
& \mathrm{h}_{\mathrm{b}}=\frac{3}{8} \mathrm{~h}_{1, \mathrm{j}}+\frac{3}{4} \mathrm{~h}_{1, \mathrm{j}-2}-\frac{1}{8} \mathrm{~h}_{1, \mathrm{j}-4}
\end{aligned}
$$

and

$$
\mathrm{v}_{\mathrm{a}}=\frac{3}{8} \mathrm{v}_{2, \mathrm{j}-1}+\frac{3}{4} \mathrm{v}_{2, \mathrm{j}-3}-\frac{1}{8} \mathrm{v}_{2, \mathrm{j}-5}
$$

Momentum:

where:

$$
\mathrm{v}_{4, \mathrm{j}}=\frac{\mathrm{M}}{\mathrm{N}}
$$

$$
\begin{aligned}
M=\frac{\Delta x}{\Delta t} & \left(v_{b}-\frac{5}{8} v_{4, j-1}+\frac{1}{24} v_{4, j-3}\right)+v_{2, j-1}\left(v_{2, j-1}-v_{2, j}-\frac{q \cdot \Delta x}{h_{a}+h_{3, j}}\right) \\
+ & g\left(S \cdot \Delta x-2\left(h_{3, j}-h_{a}\right)\right)+\frac{\alpha}{2} \cdot \frac{\Delta x}{\Delta t}\left(v_{2, j-1}-2 \cdot v_{b}+v_{2, j}\right) \\
N & =\frac{5}{12} \cdot \frac{\Delta x}{\Delta t}+v_{2, j}-v_{2, j-1}+\frac{\Delta x}{h_{a}+h_{3, j}}\left(\frac{f}{4} \cdot v_{2, j-1}+q\right) \\
h_{a} & =\frac{3}{8} h_{3, j}+\frac{3}{4} h_{3, j-2}-\frac{1}{8} h_{3, j-4}
\end{aligned}
$$

and

$$
\mathrm{v}_{\mathrm{b}}=\frac{5}{12} \mathrm{v}_{2, \mathrm{j}}+\frac{5}{8} \mathrm{v}_{2, \mathrm{j}-1}-\frac{1}{24} \mathrm{v}_{2, \mathrm{j}-3}
$$




\subsubsection{Critical Flow at Downstream Boundary}

Some computer runs were programmed to calculate critical depth and velocity at the downstream boundary (free overfall) when the Froude number there was less than unity. The critical depth, $h_{c}$, was then calculated from

$$
h_{c}=\left(\frac{v_{4, j} \cdot v_{2, j} \cdot\left(h_{3, j}\right)^{2}}{g}\right)^{\frac{1}{3}}
$$

using the iterative procedure of Stanton (1965). Then,

$$
\mathrm{v}_{\mathrm{c}}=\sqrt{\left(\mathrm{g} \cdot \mathrm{h}_{\mathrm{c}}\right)}
$$

Since the flow surface would be depressed immediately upstream of the overfall, for critical flow conditions at the overfall, $h_{3, j-2}$ and $v_{4, j-1}$ were to be recalculated using $h_{3, j}=h_{c}$ and $v_{4, j}=v_{c}$ in the equations for these values. The whole procedure was to be repeated as often as necessary to make the differences between successive values of $h_{3, j}$ and $v_{4, j}$ insignificant. However, test runs using this procedure gave spurious results due to the chosen value of $\Delta x$ being too large to describe accurately the form of the drawdown curve of the water surface caused by the free overfall (Schaake, 1965). On this account and because a finer mesh would increase computer time considerably without materially affecting the overfall hydrograph, the effect of the free overfall when the flow on the surface was subcritical was ignored in all our computer runs. This follows the procedure adopted by Morgali and Linsley (1965) and by Schaake (1965).

\subsection{Discussion of the Numerical Solutions}

Physical models used as standards by which the mathematical models are judged should be assessed as to their reliability. From our individual laboratory hydrographs it is apparent that variations occur between similar test runs, i.e. with the same overall conditions obtaining. By taking the mean flows from two similar runs, a more representative hydrograph for specified input data was obtained.

In the computer runs made to study the influence of the various parameters involved, it was evident that the steep accession and recession limbs of the hydrographs were not materially affected by changes in any of the parameters considered.

Thus, no attempt was made to optimize the friction coefficient or the surface rugosity. In fact, in most of the computer runs, the same value of surface rugosity was used to represent quite different surface properties. Nevertheless, despite these various anomalies, the results obtained show a close correlation between the computed and observed hydrographs. 


\subsubsection{Influence of Various Parameters on Equilibrium Flow}

Of prime interest in this investigation was the effect of applying a stabilizing factor (Vreugdenhil, 1968) to an unstable explicit scheme (Liggett and Woolhiser, 1967b). A diffusing scheme (when $\alpha=1$ ) has greater stability than the unstable scheme (when $\alpha=0$ ). Other runs made with different values of $\alpha$ gave intermediate results. $\alpha=0.8$ showed slightly improved stability initially, than when $\alpha=1$, but displayed greater instability as time progressed. The diffusing method is reputedly inaccurate (Vreugdenhil, 1968), though this is not always evident, since a smooth mean curve drawn through and between the plotted points would be equally representative of the hydrograph generated with $\alpha=0$ or with $\alpha=1$. Evidently, a value of á approaching unity will give best results (Wylie, 1971).

The effect of specifying the Reynolds number (TRANR) at which flows are assumed to change from laminar to turbulent is only slight and of no material consequence in the range of flows usually obtaining. In most computer runs, therefore, flows were assumed to be turbulent (TRANR $=0$ ) during the period when rain occurred and to become laminar (TRANR $=500)$ when rain ceased (Yu and McNown, 1964).

The surface rugosity appeared to have a negligible effect on the results in the range over which it was examined.

Contrary to expectation, an increase in the time increment improved the stability of the results up to a point. All the combinations of $\Delta t$ and $\Delta x$ employed in the various computer runs satisfied the Courant condition for stability.

Besides doubling the computer time, halving $\Delta \mathrm{x}$ did not improve the accuracy of the plotted flows. Therefore, in all other computer runs the number of length increments employed was fixed at 10 , this being a sufficient number of plotted points for the definition of the flow over its entire length.

\subsubsection{Explicit Scheme using Backward Differences for Supercritical Flow and Implicit Scheme}

It is apparent that both the explicit scheme using backward differences for supercritical flow (after Schaake, 1965) and the implicit scheme (after Crank and Nicolson, 1947), produced similar results for approximately the same computer running-time. Wylie (1971) found the implicit scheme to be stable when $\Delta t=0.2$ $\mathrm{s}$ and very unstable when $\Delta t=0.1 \mathrm{~s}$, for the particular values used for the other parameters. A value of $\Delta t=0.5 \mathrm{~s}$ produced acceptable stability and makes the scheme economical in use.

Comparison of the two procedures used in the solution of the implicit scheme showed only insignificant differences in the computed flows. Three or four iterations were necessary for convergence and often, when the value of the 
accelerating factor $\omega$ was increased to 1.1 , additional iterations were required. A value of $\omega$ of only 1.04 was found in some instances to accelerate convergence slightly, but in other instances it led to the calculation of negative depths and velocities, particularly towards the end of the recession limb of a hydrograph. The results plotted in Figure 5.2 for $\omega=1.1$ were obtained by applying a decelerating factor $(\omega=0.7)$ when successive iterations showed that excessive overrelaxation was being applied, as suggested by Bindon (1971).

In some runs, when convergence was difficult and solutions oscillated between two values, the two values were averaged. However, there appeared little to recommend one method of ensuring convergence in preference to the other in the few instances in which these were applied.

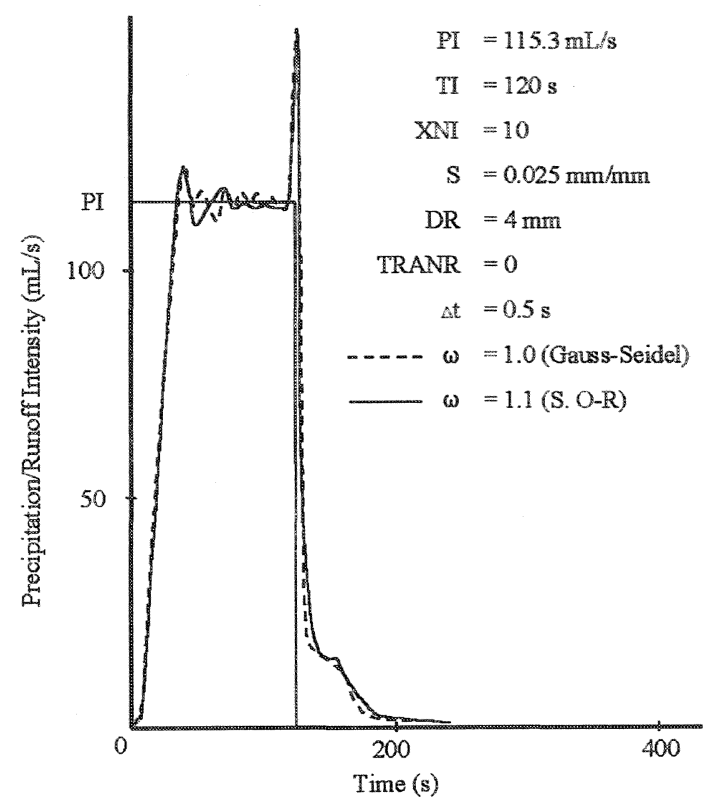

Figure 5.2 Computed hydrographs showing anomalous pip and hump. $\mathrm{PI}=$ rain intensity; $\mathrm{TI}=$ duration of rain; $\mathrm{XNI}=$ number of distance intervals.

\subsection{Discussion}

In the case of laminar flow throughout the run there is a pronounced over-run or pip as equilibrium flow is first reached. This phenomenon may be related to the similar pip often occurring at the cessation of rain and is discussed later. If required, it might be avoided by using a very small value of $\Delta t$, (though this would be uneconomical). 
In general, a single pronounced pip occurring at equilibrium flow appears to be associated only with laminar flow equations.

Observed hydrographs are more closely reproduced by the implicit scheme than by those of the explicit scheme, while both numerical solutions produced satisfactory plots.

Only one program was run in the case of the plot shown in Figure 5.3 and this gave close correlation between computed and lab hydrographs. It should be observed in the plot of the explicit scheme hydrograph in Figure 5.3 up to a to a time lapse of $114 \mathrm{~s}$, that it is the physical model's hydrographs that throw doubt on its reliability as a standard for judging the mathematical models.

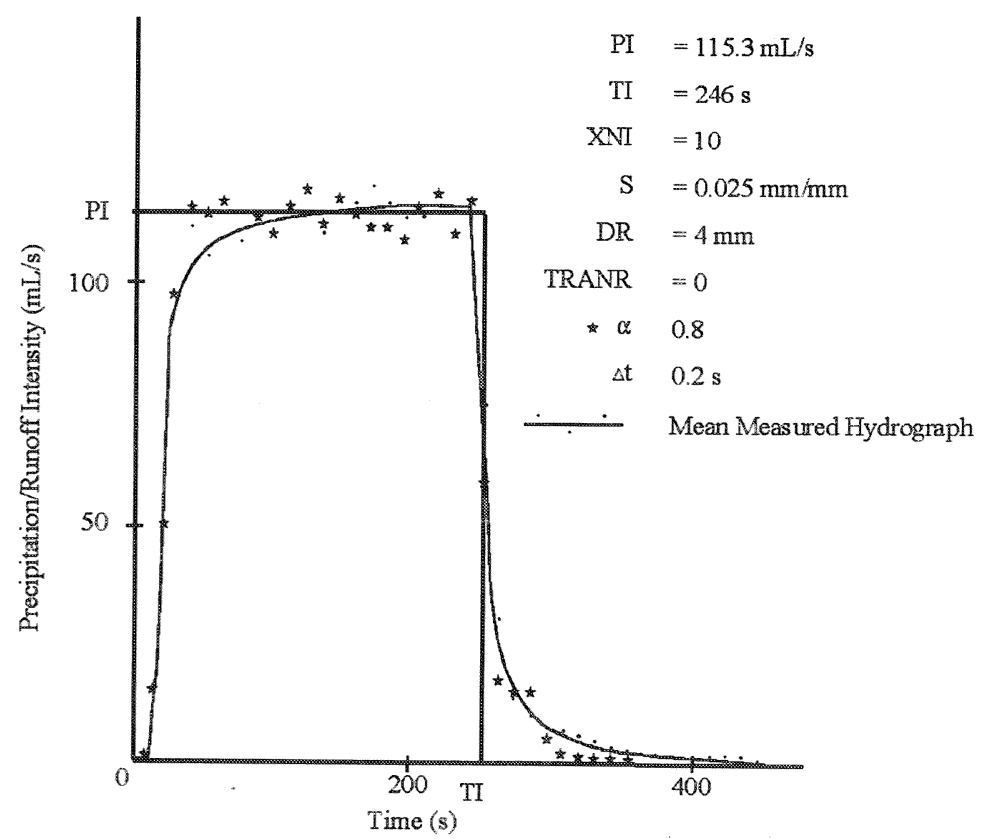

Figure 5.3 Comparison between computed and observed hydrographs.

* denotes computed point; denotes observed point.

Many of the computed flows fell on or close to the laboratory hydrographs. In some instances, however, the differences between computed and measured flows were as much as $15 \%$ of the latter (ignoring pips at the start or end of equilibrium flows).

The equilibrium-flow rate is always reached sooner in the mathematical models than in the physical model. This is a shortcoming of the mathematical models which could possibly be avoided by using a very small $\Delta t$. This would entail considerably increased computer running-times without materially improving the resulting hydrographs (not an economical proposition). 


\subsubsection{Comparison of Hydrographs with Experiments}

The better-fitting computer-generated hydrographs shown in Figures 5.4 and 5.5 all resemble fairly closely, the experimental hydrographs described in the next chapter (Johanson, 1967). In general, the computer generated equilibrium flows are higher, and the later recession flows are lower, than the corresponding laboratory hydrographs.

\subsection{The Anomalous Hydrograph Pip}

Several of our computed hydrographs showed a sharp increase in the flow rate when rain ends. In general this occurred when the computed flow situation changed from turbulent to laminar flow, in accordance with the conclusions reached by some investigators.

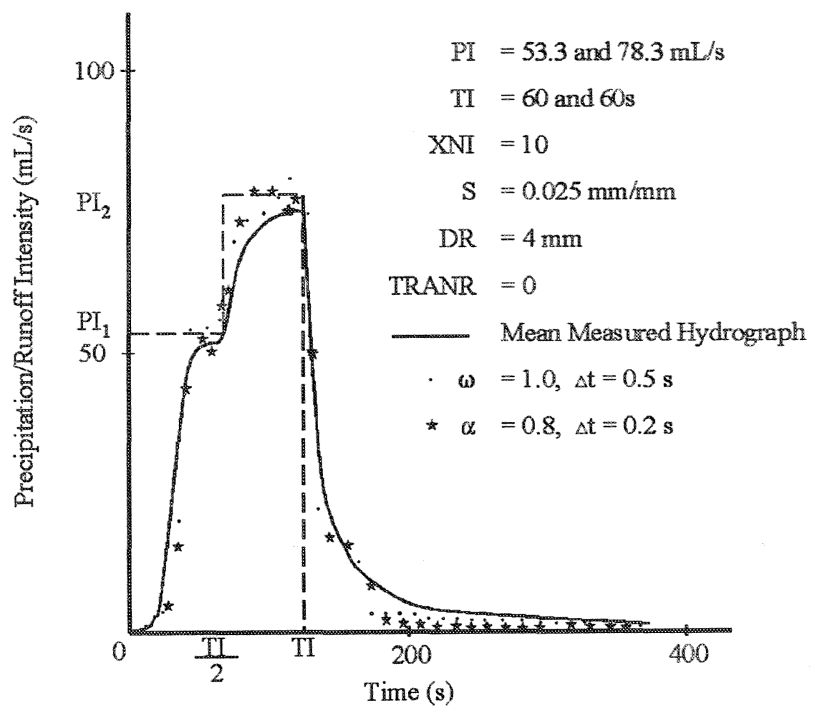

Figure 5.4 Comparison for step increase in rain.

Yu and McNown (1964) and Izzard (reported by Abdel-Razaq et al., 1967) observed this phenomenon on their measured hydrographs at the time when rain ceased. The former concluded that the cessation of rain falling onto the shallowwater flow was the reason for this effect. Although the rain entered the flow with no net momentum in the direction of flow and so retards the flow, the magnitude of this retardation is so small that its cessation could not cause this rather dramatic occurrence. 


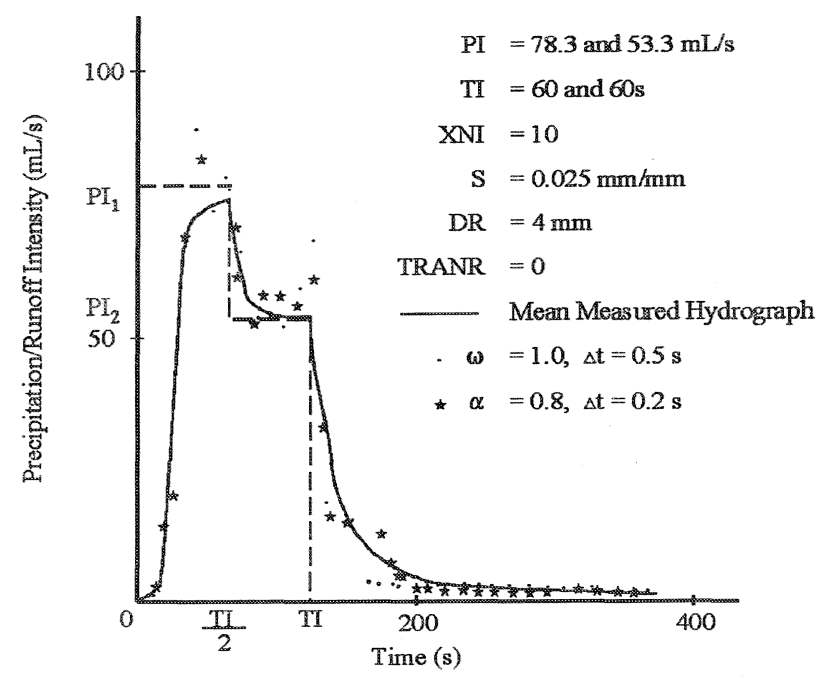

Figure $\mathbf{5 . 5}$ Comparison for step decrease in rain.

The significance of the momentum exchange term, $\frac{q v}{h}$ in the momentum equation is thus small (Morgali and Linsley, 1965). They found that the pips occur primarily in the transitional region from turbulent to laminar flow and they inferred that the rain caused flows that would otherwise be laminar to become turbulent.

Abdel-Razaq et al. (1967) report that in Izzard's experiments the pip occurred in some instances at low Reynolds numbers (in the laminar range) and did not always occur at high Reynolds numbers (in the turbulent range) and therefore, they doubt the validity of the conclusion of Yu and McNown. They concluded from their own experiments that the pip was caused by a change in the friction slope when rain ceased. This was explained by the greater frictional force retarding the flow during rain, than opposed it after rain stopped. They found that with a constant friction slope, the flow immediately after cessation of rain was less than the equilibrium rate, so that no pip appeared in the hydrograph.

As stated earlier, our computed hydrographs show that whenever a pip appeared at the cessation of rain it was in a run programmed to change from turbulent to laminar flow at this time. In instances where the flow was laminar or turbulent throughout, no significant pip occurred. The pip is to some extent dependent on the time interval used; when $\Delta t$ was small enough, the pip did not appear. The length interval used may also be significant - when $\Delta x$ was halved, the flow at cessation of rain was reduced. Indeed, the value of $\Delta x$ affects indirectly the value of the friction coefficient (Yu and McNown, 1964), and this may be the significant factor here. 
In general, the pip was least pronounced when the unstable explicit scheme was run; more so when the explicit scheme incorporating backward-difference equations was used; and was most pronounced when the implicit scheme was employed. No pip appeared at the cessation of rain in the experimental results, but an excessively high flow was recorded $6 \mathrm{~s}$ before $\mathrm{TI}$ in one instance. The method of measuring flows on the physical model may be a factor in these differences between laboratory and mathematical models.

As suggested already, numerical procedures for the solution of the dynamic wave equations are satisfactory in the application of these equations to unsteady, non-uniform, shallow-water flow on an impervious surface. Of the mathematical models investigated here, the implicit scheme showed greatest stability in most instances, with the explicit scheme employing backward differences for supercritical flows running a close second in an economic comparison of the models. The explicit scheme employing central differences for all flows did not appear in as good a light, even with a stabilizing factor approaching unity, and the use of this unstable scheme cannot be recommended.

No definite conclusions can be drawn regarding the accuracy of the implicit scheme over the explicit scheme, or vice versa. This is because of the lumping of parameters in the physical models, and because no parameter optimization was undertaken in our numerical models.

Results of our numerical model were compared with experimental results for a time-varying rain obtained from the laboratory rig described in the next chapter. The same experiments were chosen as those used by James and Johanson (1999) to develop the Initial Storage Theory (IST) described in the previous monograph in this series.

\subsection{The Anomalous Hydrograph Hump}

On all the computer-generated hydrographs, and on many of the measured ones also, a hump appears in the recession limb near the end of the initial rapid decrease in flow after cessation of precipitation as shown in Figure 5.6. Yu and McNown (1964), found this problem to be due to the transition from turbulent to laminar flow. The Reynolds numbers and friction factors (24/Re) calculated at the overfall over the region of this region of our hydrographs, even where the hump was marked, do not substantiate this.

In a chapter in an earlier book (James and Johanson, 1999) we discuss a black-box method that appears to be easier than the numerical approaches discussed above. That discussion in that chapter more clearly defines the anomalous hump. 


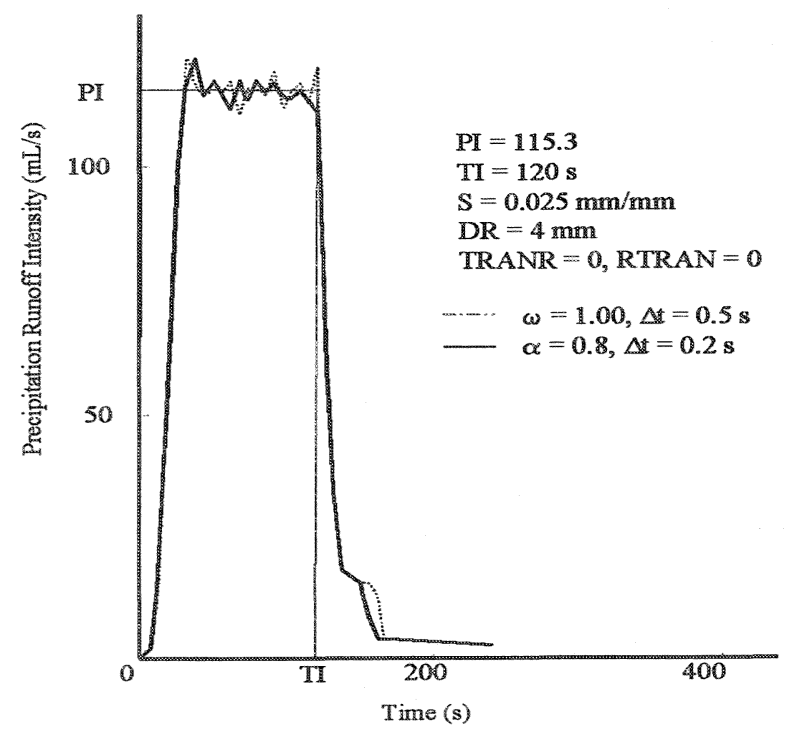

Figure 5.6 Typical plots showing the anomalous hump on the recession limb.

\section{References}

Abbott, M.B. 1966. Introduction to the method of characteristics. Elsevier, NY.

Abbott, M.B. and Inonescu, F. 1967. On the numerical computation of nearly horizontal flows. J. Hydraul. Res. (Netherlands), 5(2):98-117.

Abdel-Razaq, A.Y., Viessman, W. and Hernandez, J.W. 1967. A solution to the surface runoff problem. Proc. ASCE, J. Hyd. Div., HY6:335-352, Nov.

Amein, M. Streamflow routing on computer by characteristics. 1966. Water Resources Res., 2(1):123-130.

Amein, M. 1968. An implicit method for numerical flood routing. Water Resources Res., 4(4):719-726, August

Bindon, J.P. 1971. Private communication, April.

Brakensiek, D.L. 1966. Hydrodynamics of overland flow and nonprismatic channels. Trans. ASAE, 9(1):119-122.

Brakensiek, D.L. 1967. Finite differencing methods. Water Res. Res., 3(3):847-860.

Brakensiek, D.L., Heath, A.L. and Comer, G.H. 1966. Numerical techniques for small watershed flood routing. U.S. Dept. of Agriculture, ARS 41-113.

Chen, C. and Hansen, V.E. 1966. Theory and characteristics of overland flow. Trans ASAE, 9(1):20-26.

Chow, V.T. 1959. Open-Channel Hydraulics. Mcgraw-Hill, New York

Chow, V.T. 1969. Spatially-varied flow equations. Water Resources Res., 5(5):11241128. 
Daily, J.W. and Harleman, D.R.F. 1966. Fluid dynamics. Addison-Wesley, Mass.

Eagleson, P.S. 1970. Dynamic hydrology. McGraw-Hill, New York.

Fenzl, R.N. 1965. Computer analysis of overland flow. Discussion in Proc. ASCE, J. Hyd. Div., HY6, 224-227, Nov.

Flugge, W. 1962. Handbook of engineering mechanics. Mcgraw-Hill, New York

Grace, R.A. and Eagleson, P.S. 1965. Similarity criteria in the surface runoff process, M.I.T. Dept. Civil Eng., Hydrodynamics Lab. Rept. 77

Grace, R.A. and Eagleson, P.S. 1966. The modelling of overland flow. Water Resources Res., 2(3):393-403.

Harbaugh, T.E. 1967. Difference solutions of the shallow water equation. Discussion in Proc. ASCE, J. Eng. Mechs. Div., EM5:186-190, Oct.

Henderson, F.M. 1966.Open-channel flow. Macmillan, New York.

Henderson, F.M. and Wooding, R.A. 1964. Overland flow and groundwater flow from a steady rainfall of finite duration. J. Geophys. Res,, 69(8):1531-1540, Apr

Holsters, H. 1961. Remarques sur la stabilite dans les calculs, de maree. Proc. Symp. Maths. - Methods of physical.oceanography. Hamburg.

Houghton, D.D. and Kasahara, A. 1968. Nonlinear shallow fluid flow over an isolated ridge. Communications in Pure and Applied Maths., XXI, 1-23.

Isaacson, E., Stoker, J.J. and Troesch, A. 1958. Numerical solution of flow problems in rivers. Proc. ASCE, J. Hyd. Div., HY5, Oct.

Iwagaki, Y. 1955. Fundamental studies on the runoff analysis by characteristics. Disaster Prevention Research Institute Bulletin No. 10, Kyoto Univ., Dec.

Izzard, C.F. and Augustine, M.T. 1943. Prelim. report on analysis of runoff from simulated rainfall on a paved plot. Trans. Am. Geophys. Union, Part 2:500-509

Izzard, C.F. 1946.Hydraulics of runoff from developed surfaces. Proc. Highway Res. Board, 129-146

James, W. and Horne, C.W.D. Dec. 1969. Numerical computations for tidal propagation in the St. Lucia Estuary. Civ. Eng. in S.A., 11(12):323-326.

James, W. and R.C. Johanson. 1999. "A Note on an Inherent Difficulty with the Unit Hydrograph Method." Journal of Water Management Modeling R204-01. doi: 10.14796/JWMM.R204-01.

James, W., S.C. Wylie and R.C. Johanson. 2000. "A Laboratory Rig for Testing Runoff from Paved Surfaces." Journal of Water Management Modeling R206-06. doi: 10.14796/JWMM.R206-06.

Johanson, R.C. 1967. System analysis of the rainfall-runoff process. M.Sc.Eng. dissertation, University of Natal, Aug.

Leendertse, J.J. 1967. Aspects of a computational model for long-period water-wave propagation. RAND Memorandum RM-5294-PR, Santa Monica, Calif.

Liggett, J.A. 1959. Unsteady open channel flow wit-h lateral inflow. Tech. Rept. 2, Dept. Civil Eng., Stanford University.

Liggett, J.A. and Woolhiser, D.A. 1967. Difference solutions of the shallow-water equation. Proc. ASCE, J. Eng. Mechs. Div, EM2, 39-71, April

Liggett, J.A. and Woolhiser, D.A. 1969. Difference solutions of the shallow-water equation. Closure in Proc. ASCE, J. Eng. Mechs. Div., EM 1:303-311, Feb.

Lighthill, F.R.S. and Whitham, G.B. 1955. On kinematic waves, 1. Flood movement in long rivers. Proc. Roy. Soc. Lond., A, 229:281-316, May

Massey, B.S. 1968. Mechanics of fluids. van Nostrand, New Jersey. 
McCool, D.K. Gwinn, W.R. Ree, W.O. and Garton, J.E. 1966. Spatially varied steady flow in a vegetated channel. Trans. ASAE, 9(3):440-444.

Morgali, J.R. and Linsley, R.K. 1965 Computer analysis of overland flow. Proc. ASCE, J. Hydraul. Div., 91(HY3):81-100, May.

Ragan, R.M. 1966. Laboratory evaluation of a numerical flood routing technique for channels subject to lateral inflows. Water Resources Res., (211):111-121.

Richtmyer, R.D. 1957 Difference methods for initial value problems. Interscience.

Richtmyer, R.D. 1962. A survey of difference methods for nonsteady fluid dynamics. NCAR Tech. Notes 63-2, Natl. Center for Atmos. Res., Boulder, CO.

Robertson, A.F., Turner, A.K., Crow, F.R. and Ree, W.O. 1966. Runoff from impervious surfaces under simulated rainfall. Trans. ASAE, 913:343-346

Schaake, J.C., Jr. 1965. Synthesis of the inlet hydrograph. Tech. Rept. 3, Storm Drainage Research Project, Dept. San. Eng. \& Wat. Res., Johns Hopkins U

Schaake, J.C., Jr. 1971. Private communication, March.

Schreiber, D.L. 1970. Overland flow simulation by a nonlinear distributed parameter model. Ph.D. thesis, Washington State Univ.

Smith, G.D. 1965. Numerical solution of partial differential equations. OUP.

Terzidis, G. and Strelkoff, T. 1965. Computer analysis of overland flow. Discussion in Proc. ASCE, J. Hyd. Div., HY6:236-238, Nov.

Vreugdenhil, C.B. 1966. The influence of the friction term on the stability of difference methods for hydraulic problems. Der Ingenieur, 78(20):B92-B94.

Vreugdenhil, C.B. 1968. Difference solutions of the shallowwater equation. Discussion in Proc. ASCE, J. Eng. Mechs. Div., EM1:334-339, Feb.

Webber, N.B. 1965. Fluid mechanics for civil engineers. Spon, Lond.,

Woo, D-C. and Brater, E.F. 1962. Spatially varied flow from controlled rainfall. Proc. ASCE, J. Hyd. Div, HY6: 31-56, Nov.

Wood, D.J. 1966. An explicit friction factor relationship. Civil Engineering, ASCE, 6061, Dec.

Wooding, R.A. 1965. A hydraulic model for the catchment stream, Problem 1, Kinematic wave theory. J. Hydrol., 3:254-267.

Wooding, R.A. 1965b. A hydraulic model for the catchment stream, Problem II, Numerical solutions. J. Hydrol., 3:268-282.

Woolhiser, D.A. and Liggett, J.A. 1967. Unsteady, one-dimensional flow over a plane - the rising hydrograph. Water Resources Res., 3(3):753-771

Woolhiser, D.A. 1969. Private communication, December .

Wylie, S.C. 1971. An appraisal of some numerical solutions of the dynamic wave equations. M.Sc.Eng. Dissertation, University of Natal, Aug.

Yu, Y.S. and McNown, J.S. 1964. Runoff from impervious surfaces. J. Hydraul. Res., 2(1):3-24 
